\title{
Vertical Distribution and Movements of Larval Redfishes (Sebastes spp.) in the Southern Gulf of St. Lawrence
}

\author{
T. J. Kenchington ${ }^{1}$ \\ Department of Fisheries and Oceans, Marine Fish Division \\ Bedford Institute of Oceanography, P. O. Box 1006 \\ Dartmouth, Nova Scotia, Canada B2Y 4A2
}

\begin{abstract}
The vertical distribution of larval redfishes (Sebastes spp.) in the Gulf of St. Lawrence in May is described, based on published survey data. In daylight, the larvae are most abundant between 11 and $30 \mathrm{~m}$ depth but are not very concentrated with depth and are taken from the surface to at least $180 \mathrm{~m}$ depth. At night, their depth mode rises to the uppermost $10 \mathrm{~m}$; a highly significant change in vertical distribution. This pattern contrasts with that found by a previous study in the Gulf of Maine where the larvae appeared to be highly concentrated at certain depths but showed no diel migration. Possible reasons for these differences include the sizes of larvae caught, hydrographic conditions and the species composition of the redfishes in the two areas. Based on these results, it is proposed that surveys for the abundance or geographic distribution of redfish larvae should use oblique, rather than horizontal tows.
\end{abstract}

\section{Introduction}

The vertical distribution and movements of ichthyoplankton strongly influence their horizontal drift migrations, the amount of food available to larval and later stages and, hence, their growth and survival rates. Moreover, knowledge of that distribution is important for survey design. Larval surveys for abundance estimation or for the mapping of geographic and seasonal distributions must use sampling gears and tow profiles appropriate to the vertical distributions of the species of concern.

The Atlantic redfishes (Sebastes spp.) are of major importance to the groundfish fisheries of the Northwest Atlantic. In consequence, the occurrence of larvae of these ovo-viviparous fish has been systematically recorded during several ichthyoplankton survey programs in this region (e.g. Marak et al., 1962; O'Boyle et al., 1984). However, little is known of their vertical distribution and this limits the interpretation of those survey data. Tåning (1949), Templeman (1959), Hansen and Anderson (1961), Corlett (1961), Dietrich et al. (1961) and Raitt (1964) have suggested that most redfish larvae live in a sub-surface layer, with the depth of its upper boundary being variously estimated as 5 or 10 $\mathrm{m}$ and that of its lower boundary as 30 to $60 \mathrm{~m}$. Magnússon et al. (1965) have shown that, within this layer in the Irminger Sea, the larvae are more abundant at 15 to 18 $\mathrm{m}$ than at other depths. It is, however, also clear that some redfish larvae occur much deeper than $60 \mathrm{~m}$, while a few have been taken from the neuston (Templeman, 1959; Faber, 1976; Sameoto, 1984).
Only Kelly and Barker (1961) have published a relatively precise description of the vertical distribution of these larvae. They studied the redfish in the western Gulf of Maine in the summer, using an Isaacs-Kidd midwater trawl fitted with a $9 \mathrm{~mm}$ mesh liner and an opening/closing mechanism. In late July, they found larvae at all depths fished $(0$ to $100 \mathrm{~m}$ ) except at the surface itself but most ( $98 \%$ of catches-per-tow) were taken between 10 and $30 \mathrm{~m}$ inclusive. In September, on the basis of relatively few catches, some larvae appeared to be living deeper; the mean depth of capture being about $100 \mathrm{~m}$, though significant catches were still taken at $10 \mathrm{~m}$. There was little evidence of a diel cycle in depth distribution in either season, although the catchability of the larvae seemed much higher at night than by day (Kelly and Barker, 1961). This apparent lack of a diel cycle in vertical distribution was seemingly supported by a recent study off Nova Scotia (Sameoto, 1984), though, given the sample splitting protocol employed, it is doubtful whether sufficient redfish larvae were taken to detect such movements.

In contrast, Magnússon et al. (1965) found a marked diel change in catches of larval redfish taken by Icelandic High Speed samplers in the Irminger Sea. They worked their gear at $3 \mathrm{~m}, 15$ to $18 \mathrm{~m}$ and 25 to $30 \mathrm{~m}$ depths, during a survey of larval horizontal distributions. The observed diel cycle involved a small overall increase in catch rates at night along with a major nocturnal increase in the relative catch rate at $3 \mathrm{~m}$ and concomitant decreases at greater depths, particularly at 25 to $30 \mathrm{~m}$. Similarly, Beltestad et al. (1975), in an 
acoustic study in the Barents Sea, found that redfish larvae were spread over a wide range of depths in daylight but were concentrated in a layer at 6 to $15 \mathrm{~m}$ depth at night.

While Kelly and Barker (1961) adequately described the vertical distributions which they studied, their results are only directly applicable to redfish in the Gulf of Maine in the summer, and indeed only to the larger larvae $194 \%$ of the larvae in their catches were $>15 \mathrm{~mm}$ in length, whereas redfish larvae are released in the spring at $<10 \mathrm{~mm}$ length (Kenchington, 1984)). The limited information available from other areas is insufficient to determine to what extent Kelly and Barker's (1961) conclusions are more broadly relevant. The studies by Magnússon et al. (1965) and Beltestad et al. (1975) have demonstrated at least one inter-regional difference, in that redfish larvae in the Irminger and Barents Seas show a pattern of diel vertical migration, whereas those in the Gulf of Maine apparently do not. To add to this complexity, recent revisions to the taxonomy of Sebastes have shown that four major taxa occur in the North Atlantic ${ }^{2}$. Of these, S. fasciatus predominates on the Scotian Shelf (Ni, 1982; Kenchington, 1984 ) and is most probably the only significant species in the Gulf of Maine and hence in Kelly and Barker's (1961) data. Magnússon et al. (1965), on the other hand, would have encountered primarily $S$. mentella in the Irminger Sea, while both S. marinus and S. mentella are abundant in the Barents Sea (Kenchington, 1984). Thus, it remains necessary to examine the detailed vertical distribution of redfish larvae in a variety of areas for comparison with Kelly and Barker's (1961) results.

Kohler et al. (1974a, b, 1975, 1976, 1977) have published an extensive set of data on the ichthyoplankton of the southern Gulf of St. Lawrence. This is of limited value in mapping the horizontal distribution of redfish larvae, since most of the survey transects ended near the southern edge of the Laurentian Channel, while the centre of redfish distribution in the Gulf of St. Lawrence is further north (Fig. 1). Indeed, the data set is not ideal even for a study of vertical distribution, particularly because the nets were not equipped with closing gear, the stations were geographically-dispersed and larval sizes were not recorded. Nevertheless, in the absence of more appropriate studies, this data set does contain useful information on the vertical distribution and movements of Sebastes larvae in the Gulf of St. Lawrence. A subset of those data is used in the present study to illustrate that vertical distribution, to provide some extension to the results obtained by Kelly and Barker (1961) and to give some guidance for the design of larval redfish survey programs. The analyses reported here replace a preliminary version presented by Kenchington (1984).

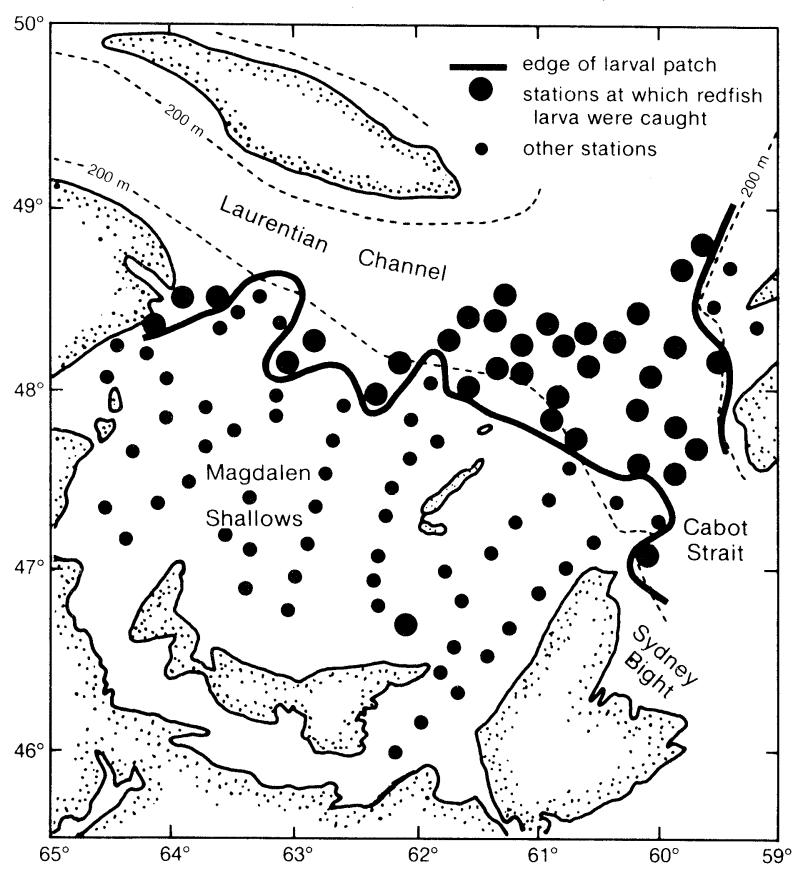

Fig. 1. Chart of the southern Gulf of St. Lawrence showing: a typical horizontal distribution of redfish larvae (based on meter net catches at various depths on Cruise P100), the congruence between the edge of the main redfish larval patch and the $200 \mathrm{~m}$ bathymetric contour, and the distribution of survey stations within and outside the larval patch. (Data from Kohler et al., 1977.)

\section{Methods}

The field methods have been described in detail by Kohler et al. (1974a, b, 1975, 1976, 1977). In short, 35 survey cruises were carried out between 1965 and 1975 . Most of the surveys consisted of a series of transects across the Magdalen Shallows and the southern fringe of the Laurentian Channel, though some were more restricted in coverage and a few extended across Cabot Strait or into Sydney Bight. A variety of gears were worked as horizontal or stepped-oblique tows, with the particular selection varying between cruises and stations. The survey work proceeded through night and day.

Among the gear types used, only the Miller Samplers (Miller, 1961) were worked at a sufficient variety of depths for vertical profiling of larval distributions. These nets were set at 554 stations on 10 cruises and were towed at a wide variety of depths, with up to 14 samplers stacked on a single wire. Tow duration was fixed at $30 \mathrm{~min}$. (deviations from this duration, if any, not being recorded). The Miller Samplers were not equipped with closing mechanisms and hence the recorded catches from deeper tows may have been contaminated by fishing at lesser depths as the gear

\footnotetext{
${ }^{2}$ Nomenclature used here follows Robins et al. (1986) for continuity with earlier work, pending final acceptance or otherwise of the revisions proposed by Fernholm and Wheeler (1983) and Kenchington (1984).
} 
was shot and hauled. Furthermore, the Miller Samplers were towed at only 2-1/2 knots and, since they have a mouth diameter of only $0.1 \mathrm{~m}$, there may have been considerable net avoidance by larger larvae. No length measurements were made of redfish captured by the Miller Samplers nor were they identified to species. Indeed, reliable specific identification of Sebastes larvae is not yet possible (Kenchington, 1984).

Most of the redfish larvae found by these surveys were taken over the deep water of the Laurentian Channel (Fig. 1). Miller Sampler catches-per-tow in this area therefore tended to be greater than those taken at the same depths in other parts of the surveyed area. Since the depths at which the Miller Samplers were deployed varied between stations (not least because, at some Laurentian Channel stations, they were towed at depths greater than the bottom depths at the Magdalen Shallows stations), measured depth distributions inevitably are, in part, artifacts of an interaction between sampling patterns and redfish abundance in different areas. This effect was reduced by the selection of stations for analysis (see below) but cannot be entirely eliminated from any geographically extensive survey.

Only on cruises P071 and P100 (in May 1970 and May 1972 respectively) did the Miller Samplers take substantial numbers of redfish. Data from other cruises were insufficient to prepare meaningful profiles and they were therefore discarded from the analyses. Of the 36 stations on cruise P071 at which redfish were caught by Miller Samplers, 18 were situated between Cabot Strait and $62^{\circ} \mathrm{W}$ over water depths greater than $200 \mathrm{~m}$. At some of these stations, Miller Samplers were towed at depths down to $183 \mathrm{~m}$. Data from these 18 deep, geographically homogeneous stations were used to prepare a general depth profile for redfish larvae. No directly equivalent profile could be prepared for cruise P100 since Miller Samplers were deployed below $80 \mathrm{~m}$ depth at only two stations on that cruise.

On cruise P071, only three deep stations were occupied at night and so no meaningful comparison of day and night depth distributions of larvae could be prepared. More data were, however, available for cruise P100. Stations on this cruise located over bottom depths $\geqslant 100 \mathrm{~m}$ were selected and classed as "daylight" (0500-1930 hr), "darkness" (2100-0330 hr), "dusk" or "dawn". Data from these 16 daylight, 8 darkness and 32 combined (day, dark, dusk and dawn) time-period stations were used in the preparation of three depth profiles. In the southern Gulf of St. Lawrence, the $100 \mathrm{~m}$ bathymetric contour lies very close to the $200 \mathrm{~m}$ one. In view of the maximum depth of net deployment on cruise P100, relaxing the bottom depth constraint to $100 \mathrm{~m}$ from the $200 \mathrm{~m}$ used above allowed data from an extra seven stations to be included in the profiles without adding marked distortions.
Since the gear was towed at different depths at the various stations, the data for each profile were grouped by nominal tow depth into $10 \mathrm{~m}$ deep strata, extending from immediately below the surface. Surface tow data were treated as being from a distinct stratum. At a few stations, Miller Samplers were towed at more than one depth within some strata, resulting in numbers of towsper-stratum (Fig. 2 and 3) greater than the corresponding number of stations.

Inspection of the distribution of catch size showed that these larvae were highly aggregated. Downing's (1979) fourth root transformation reduced the skew in catch size much more than did a logaritnmic transformation. Mean catches-per-tow for each stratum were therefore calculated using Downing's (1979) methods and re-transformed to numbers of larvae for presentation in the depth profiles. Standard errors of these means were calculated in the transformed state and the resulting confidence limits were re-transformed.

The transformed data were still significantly nonnormal (Kolmogorov-Smirnov $(K-S)$ test, $P<0.01$ ), preventing the use of parametric tests when comparing vertical distributions. The difference between the daylight and darkness distributions on cruise P100, as represented by the re-transformed stratum mean catches, was therefore tested using a K-S test. Depth strata below $80 \mathrm{~m}$ depth were excluded from this test since no tows were made at night at depths greater than that. The K-S tests compare only distributions (in this case the calculated mean depth distributions) and are therefore unable to account for the degree of uncertainty surrounding those distributions.

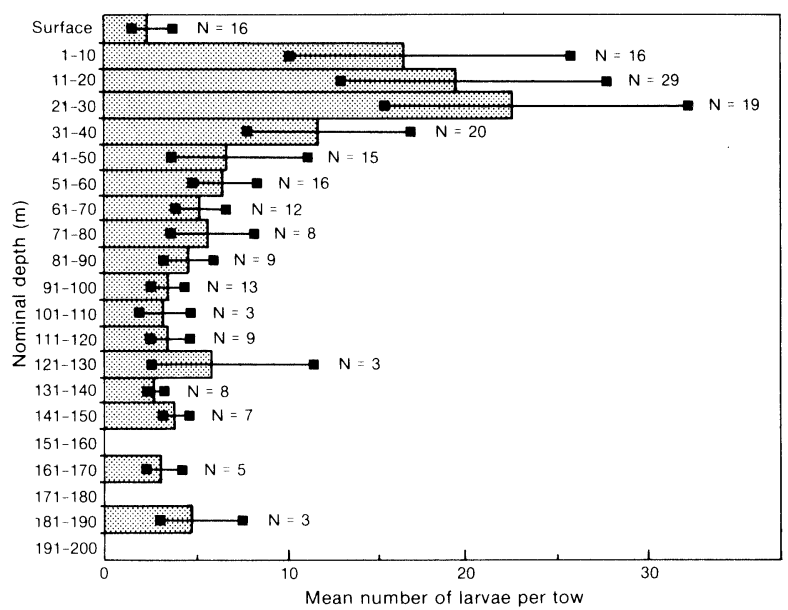

Fig. 2. Depth distribution of redfish larvae in the southern Gulf of St. Lawrence in May 1970, based on Miller Sampler catches at 18 selected stations on Cruise P071. Confidence limits are one Standard Error of stratum means calculated in fourth root space and retransformed to linear scale, $\mathrm{N}=$ number of tows in depth stratum. 


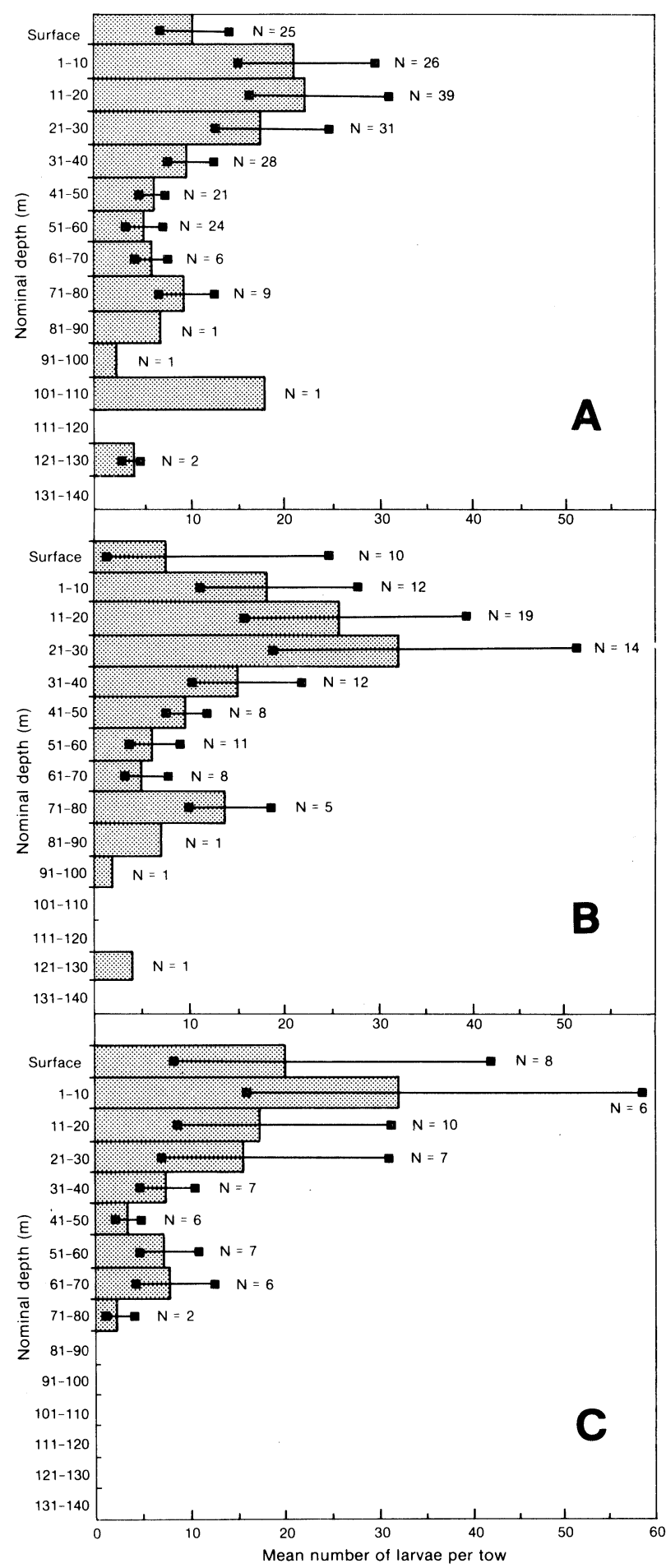

Fig. 3. Depth distributions of redfish larvae at selected stations on Cruise P100, May 1972: (A) combined times (daylight, darkness, dawn and dusk; 32 stations), (B) daylight only (16 stations), (C) darkness only (8 stations). Confidence limits are one Standard Error of stratum means calculated in fourth root space and retransformed to linear scale. $\mathrm{N}=$ number of tows in depth stratum.

\section{Results}

The calculated depth profile derived from cruise P071 (Fig. 2) shows that redfish larvae in May 1970 were broadly distributed in the top $200 \mathrm{~m}$ of the water column. Although there was a strong abundance mode between 1 and $30 \mathrm{~m}$ depth, the three strata in this range yielded only $12.5,14.7$ and $17.1 \%$ respectively of the larvae in the profile (percentages based on retransformed stratum means). Redfish larvae evidently tended to avoid the surface itself; they were several times more abundant at immediate sub-surface depths than in the neuston.

The overall profile from cruise P100 (Fig. 3A) shows that the redfish larvae in May 1972 had a generally similar depth distribution to that seen 2 years earlier. Of the few notable differences between this profile and that in Fig. 2, the slight secondary mode at 71 to 80 $m$ depth is an artifact. Inspection of the raw data (Kohler et al., 1977) shows that, by chance, this stratum was usually sampled only at stations with high redfish abundance. At none of those stations did a marked mode appear at this depth and hence the mode in Fig. $3 \mathrm{~A}$ must have resulted from the interaction of the sampling and larval distribution patterns not from any real increase in larval abundance below $70 \mathrm{~m}$. The apparent mode at 101 to $110 \mathrm{~m}$ depth was produced by a single, relatively large catch and can thus be rejected as a chance effect.

Another notable feature of the combined-times profile from cruise $\mathrm{P} 100$ is the relatively high surface catch, in comparison with that shown in Fig. 2. This can be explained by a comparison of the daylight and darkness profiles (Fig. 3B, C). In daylight, the redfish larvae had a mode at 11 to $30 \mathrm{~m}$, as on cruise P071, whereas at night the mode was at 1 to $10 \mathrm{~m}$, with a corresponding increase in surface catches. This shift of modal depth represents a highly significant (K-S test: $K=2.295$, $\mathrm{P}<0.001)$ diel change in depth distribution.

The re-transformed stratum mean catches-pertow summed over the top $80 \mathrm{~m}$ of the water column total 131 for the daylight stations and 110 for the darkness ones. Thus, if the proportion of the larvae occurring in the top $80 \mathrm{~m}$ underwent a diel change, it was compensated for by an almost equal, but opposite, change in catchability. Both the proportion and the catchability would be expected to increase at night, however, if they changed at all (cf. Kelly and Barker, 1961; Magnússon et al., 1965). Rather than assume an anomalous decrease in either factor, it is more parsimonious to conclude that neither changed markedly. Hence, the cycle in the measured profiles appears to reflect a genuine difference in depth distribution, not an artifact 
resulting from major migrations into or out of the depth range.

\section{Discussion}

The depth distributions of redfish larvae illustrated here are in general agreement with the conclusions of earlier workers (Tåning, 1949; Templeman, 1959; Kelly and Barker, 1961; Hansen and Anderson, 1961; Corlett, 1961; Dietrich et al., 1961; Raitt, 1964; Magnússon et al., 1965; Beltestad et al., 1975; Faber, 1976). The present observation of a diel cycle in depth distribution closely resembles those reported by Magnússon et al. (1965) and Beltestad et al. (1975), though the modal diurnal depth appears to be slightly deeper in the Gulf of St. Lawrence than in the Irminger Sea. There are, however, three notable differences between the present results and those reported by Kelly and Barker (1961): the latter found $97 \%$ of larvae to be between 10 and $30 \mathrm{~m}$ below the surface (compared to only $32 \%$ here), they found a marked diel cycle in catchability which does not appear in the Gulf of St. Lawrence data and they were unable to detect a diel cycle in depth distribution whereas such a cycle is shown here.

These preceived differences may be partly due to deficiencies of the two studies. The present work is based on data from only 54 stations on two cruises, whereas Kelly and Barker (1961) used 38 stations on four cruises. Both studies may therefore have measured short-term features rather than "typical" depth distributions. However, the Gulf of Maine profile in late-July 1958 was much like the one a year earlier and the Gulf of St. Lawrence data show close similarities between May 1970 and May 1972, so the differences between the data sets seem to represent more than chance alone. The use of non-closing Miller Samplers (Kohler et al., 1976, 1977) will have exaggerated the proportion of the larvae living at greater depths, while the use of arithmetic means by Kelly and Barker (1961) will have given excess weight to occasional large catches and thus exaggerated the proportion living near the modal depth. Nevertheless, the differences between the two sets of results are sufficiently marked to suggest a real difference in redfish larval depth distribution between the Gulf of St. Lawrence in May and the Gulf of Maine in July.

Two obvious reasons for such a difference are the season of the surveys and the species compositions of the redfish surveyed. Kelly and Barker (1961) estimated that the season of larval release in the Gulf of Maine begins in late April and Kenchington (1984) has shown that a few redfish larvae are present off Nova Scotia as early as February. Thus, some of Kelly and Barker's (1961) larvae will have been a few months old when caught. The use of $9 \mathrm{~mm}$ mesh in their nets will have reinforced this effect by allowing most small larvae to escape. Indeed, $93 \%$ of those that they caught were $\geqslant 15$ mm long (Kelly and Barker, 1961). The Gulf of St. Lawrence surveys (Kohler et al., 1976, 1977), on the other hand, were carried out in May and could have encountered only a few larvae more than a month old. Furthermore, the use of slowly-towed Miller Samplers would probably have also allowed the few large larvae to escape. Thus, most of the redfish caught during these surveys can have been little longer than their size at release, which is about 7 to $10 \mathrm{~mm}$ in the Gulf of St. Lawrence (Templeman, 1959). This difference in larval size may be one cause of the divergent results in the two studies.

The season of the surveys also relates to a major difference in water temperatures. In July, Kelly and Barker (1961) found redfish larvae to be concentrated within a marked thermocline, between about $10^{\circ}$ and $15^{\circ} \mathrm{C}$ and between about 10 and $30 \mathrm{~m}$ depth. Routine, detailed hydrographic measurements were not made on cruises P071 and P100. The normal pattern of water masses in May in the area surveyed by those cruises, however, shows a surface layer at $0^{\circ} \mathrm{C}$ or a little above, a sub-surface temperature minimum of about $-1^{\circ} \mathrm{C}$ at around 80 to $110 \mathrm{~m}$ depth and slightly warmer water (about $4^{\circ} \mathrm{C}$ ) below it (Loring and Nota, 1973). Clearly, larvae adapted to life at $10^{\circ}$ to $15^{\circ} \mathrm{C}$ in the Gulf of Maine in July would be constrained in depth by the thermocline to an extent that larvae adapted to $-1^{\circ}$ to $4^{\circ} \mathrm{C}$ in the Gulf of St. Lawrence in May would not be.

Another possible explanation for the observed differences in vertical distribution relates to the species of redfish present in the two areas. The larvae caught in the Gulf of Maine were almost certainly S. fasciatus, since this is the only abundant redfish there (cf. Ni, 1982; Kenchington, 1984). The species composition of adult redfish, and hence also of their larvae, in the Gulf of St. Lawrence is less clear. Meristic (Ni, 1982), maturation ( $\mathrm{Ni}$ and Sandeman, 1984; $\mathrm{Ni}$ and Templeman, 1985 ) and electrophoretic (P. J. Rubec, Maurice Lamontagne Institute, Mont-Joli, Quebec, pers. comm.) studies suggest that $S$. mentella is the most common species in deeper water, while $S$. fasciatus predominates above the $250 \mathrm{~m}$ contour and a few $S$. marinus are present in the Cabot Strait area. All three redfishes, but particularly S. mentella, are probably represented in the vertical profiles presented here. Thus, some of the divergence in larval vertical distribution and, particularly, diel migration pattern between the Gulf of Maine and the Gulf of St. Lawrence may be caused by inter-specific differences between $S$. fasciatus and $S$. mentella. It is at least noteworthy that $S$. mentella is a prominant redfish in the Gulf of St. Lawrence, the Irminger Sea and the Barents Sea, the three areas where Sebastes larvae have been shown to migrate vertically.

The available data sets do not permit a test of the relative importance of species composition, larval size and water temperature profile in determining the differ- 
ences between larval depth distributions and movements in the Gulf of Maine and Gulf of St. Lawrence.

Finally, this study has provided some basis for designing future survey programs for larval redfish. Because of their concentration at one depth (Kelly and Barker, 1961), the Gulf of Maine larvae might be efficiently surveyed using horizontal tows at about $20 \mathrm{~m}$ depth, at least in July. In the Gulf of St. Lawrence, however, the present analyses have shown that oblique tows, from the bottom or from about $200 \mathrm{~m}$ depth (whichever is shallower) would be more suitable. In neither case would surface tows be adequate since the major concentrations of redfish larvae are depressed at least a few metres below the surface in daylight.

\section{Acknowledgements}

My thanks are due to Dr A. C. Kohler for granting access to his data, to Drs R. G. Halliday, P. Hurley, M. D. Grosslein and anonymous referees for very constructive reviews of earlier drafts, and to Drs R. G. Halliday, T. D. lles, W. T. Stobo, W. D. Bowen and Mr R. N. O'Boyle (successive Chiefs and Acting Chiefs of Marine Fish Division) for permitting me to work in their Division. The analyses reported here were developed from ones completed while I was a graduate student at Dalhousie University, supported by an I. W. Killam Memorial Scholarship and by the Natural Sciences and Engineering Research Council of Canada (NSERC) through a grant to Dr I. A. McLaren. The manuscript was completed while I was a Research Associate in both the Department of Finance and Management Science, Saint Mary's University, and the Halifax Laboratory of the Department of Fisheries and Oceans, and while I was supported by a Department of Fisheries and Oceans Subvention Grant to Dr A. T. Charles, Saint Mary's University.

\section{References}

BELTESTAD, A. K., O. NAKKEN, and O. M. SMEDSTAD. 1975. Investigations on diel vertical migration of 0 -group fish in the Barents Sea. Fiskeridir. Skr. (Havunders.), 16: 229244.

CORLETT, J. 1961. Distribution of redfish larvae in the western Barents Sea. ICNAF Spec. Pub., 3: 188-193.

DIETRICH, G., H. AURICH, and A. KOTTHAUS. 1961. On the relationship between the distribution of redfish and redfish larvae and the hydrographic conditions in the Irminger Sea. ICNAF Spec. Pub., 3: 124-139.

DOWNING, J. A. 1979. Aggregation, transformation, and the design of benthos sampling programs. J. Fish. Res. Board Can., 36: 1454-1463.

FABER, D. J. 1976. Hyponeustonic fish larvae in the Northumberland Strait during summer 1962. J. Fish. Res. Board Can., 33: 1167-1174

FERNHOLM, B., and A. WHEELER. 1983. Linnaean fish speci- mens in the Swedish Museum of Natural History, Stockholm. Zool. J., 78: 199-286.

HANSEN, V. K., and K. P. ANDERSEN. 1961. Recent Danish investigations on the distribution of larvae of Sebastes marinus in the North Atlantic. ICNAF Spec. Pub., 3: 201215.

KELLY, G. F., and A. M. BARKER. 1961. Vertical distribution of young redfish in the Gulf of Maine. ICNAF Spec. Pub., 3: 220-233.

KENCHINGTON, T. J. 1984. Population structures and management of the redfishes (Sebastes spp: Scorpaenidae) of the Scotian Shelf. Ph.D. Thesis, Dalhousie University: xviii $+491 \mathrm{p}$.

KOHLER, A. C., D. J. FABER, and N. J. McFARLANE. 1974a. Eggs, larvae and juveniles of fishes from plankton collections in the Gulf of St. Lawrence during 1965, 1966 and 1967. Tech. Rep., Fish. Res. Board Can., 285: 1-164.

1974b. Eggs, larvae and juveniles of fishes from plankton collections in the Gulf of St. Lawrence during 1968. Res. Dev. Tech. Rept. Can. Fish. Mar. Ser., 490 $1-105$.

1975. Eggs, larvae and juveniles of fishes from plankton collections in the Gulf of St. Lawrence during 1969. Tech. Rep. Can. Fish. Mar. Ser., 521: 1-154.

1976. Eggs, larvae and juveniles of fishes from plankton collections in the Gulf of St. Lawrence during 1970 to 1971. Tech. Rep. Can. Fish. Mar. Ser., 645: 1-139.

1977. Eggs, larvae and juveniles of fishes from plankton collections in the Gulf of St. Lawrence during 1972 to 1975. Tech. Rep. Can. Fish. Mar. Ser., 747: 1-180.

LORING, D. H., and D. J. G. NOTA. 1973. Morphology and sediments of the Gulf of St. Lawrence. Bull. Can. Fish. Mar. Ser., 182: $147 \mathrm{p}$

MAGNÚSSON, J., J. MAGNÚSSON, and I. HALLGRÍMSSON. 1965. The "Aegir" redfish larvae expedition to the Irminger Sea in May 1961. Rit Fiskideild., 4(2): 86 p.

MARAK, R. R., J. B. COLTON, and D. B. FOSTER. 1962. Distribution of fish eggs and larvae, temperature, and salinity in the Georges Bank-Gulf of Maine area, 1955. U.S. Fish Wildl. Serv., Spec. Sci. Rep.-Fish., 411: 66 p.

MILLER, D. 1961. A modification of the small Hardy plankton sampler for simultaneous high-speed plankton hauls. Bull. Mar. Ecol., 5(45): 165-172.

NI, I-H. 1982. Meristic variation in beaked redfishes, Sebastes mentella and S. fasciatus, in the Northwest Atlantic. Can. J. Fish. Aquat. Sci., 39: 1664-1685.

NI, I-H., and E. J. SANDEMAN. 1984. Size at maturity for Northwest Atlantic redfishes (Sebastes). Can. J. Fish. Aquat. Sci., 41: 1753-1762.

NI, I-H., and W. TEMPLEMAN. 1985. Reproductive cycles of redfishes (Sebastes) in southern Newfoundland waters. J. Northw. Atl. Fish. Sci., 6: 57-63.

O'BOYLE, R. N., M. SINCLAIR, R. J. CONOVER, K. H. MANN, and A. C. KOHLER. 1984. Temporal and spatial distribution of ichthyoplankton communities of the Scotian Shelf in relation to biological, hydrological, and physiographic factors. ICES Rapp. Proc.-Verb., 183: 27-40.

RAITT, D. F. S. 1964. Scottish redfish larval investigations in 1962 with some observations on mid-ocean echo-traces. ICES J. Cons., 29: 65-72.

ROBINS, C. R., R. M. BAILEY, C. E. BOND, J. R. BROOKER, E. A. LACHNER, R. A. LEA, and W. B. SCOTT. 1986. Names of the Atlantic redfishes, genus Sebastes. Fisheries (Bethesda), 11(1): 28-29. 
SAMEOTO, D. D. 1984. Environmental factors influencing diurnal distribution of zooplankton and ichthyoplankton. J. Plankton Res., 6: 767-792.

TÅNING, A. V. 1949. On the breeding places and abundance of the redfish (Sebastes) in the North Atlantic. ICES J. Cons., 16: 85-95.

TEMPLEMAN, W. 1959. Redfish distribution in the North Atlantic. Bull. Fish. Res. Board Can., 120: 1-173. 